\title{
Pseudocapillaria (Pseudocapillaria) moraveci sp. n. (Nematoda: Capillariidae) from the stomach of Gobius paganellus (Perciformes: Gobiidae) from Vigo estuary (NW Spain)
}

\author{
Raúl Iglesias $^{1}$, Luisa Centeno ${ }^{2}$, Nuria García $^{1}$ and José M. García-Estévez ${ }^{1}$ \\ ${ }^{1}$ Laboratorio de Parasitología, Facultad de Biología, Campus Lagoas-Marcosende, Universidad de Vigo, Vigo, Spain. \\ ${ }^{2}$ Instituto Nacional de Investigaciones Agrícolas, Delta-Amacuro, Venezuela.
}

\begin{abstract}
Pseudocapillaria moraveci sp. n. (Nematoda, Capillariidae) is described from the stomach of Gobius paganellus Linnaeus (Perciformes, Gobiidae) from rocky shores of the Vigo estuary (Northwest Atlantic coast of Spain). Scanning electron microscopy reveals the absence of a dorsal cuticular membrane interconnecting the caudal lobes of male, thus confirming the assignment of this new species to the nominotypical subgenus Pseudocapillaria Freitas, 1959. Pseudocapillaria moraveci can be easily differentiated from other marine congeneric species belonging to subgenera Pseudocapillaria and Ichthyocapillaria Moravec, 1982 by its muscular oesophagus, which is distinctly thickened at the distal third, the terminal or almost terminal anus in female, the presence of a basal internal papilla on each ventrolateral caudal lobe in male, and its exclusive site preference for the stomach. In addition, the spicule, which measures $0.180-0.292 \mathrm{~mm}$ in length (4.9-7.9\% of body length) and possesses a proximal end expanded and oblique in lateral view, a narrowed middle part, and a distal end almost pointed, also distinguishes this species. Pseudocapillaria moraveci is, together with P. tomentosa (Dujardin, 1843) Moravec, 1987, the only species in the genus Pseudocapillaria that has been reported to infect members of the family Gobiidae.
\end{abstract}

Keywords: intertidal fish, rocky shores, parasites, digestive tract, taxonomy

The rock goby (Gobius paganellus Linnaeus) is found along the north-western Atlantic, from Scotland to Senegal, including the Azores, Canary and Madeira Islands, as well as the Mediterranean Sea and the Black Sea (Miller 1986, Fricke et al. 2007, Engin and Seyhan 2009). It is a common inshore and intertidal species, inhabiting under stones and in pools on sheltered rocky shores with much weed cover (Miller 1986). In the Iberian Peninsula Atlantic shores, the rock goby is one of the most abundant resident intertidal fishes, together with the bleniids Lipophrys pholis (Linnaeus) and Coryphoblennius galerita (Linnaeus) (Ibáñez et al. 1989, Faria and Almada 1999, Mazé et al. 2006). As far as we know, capillariid nematodes, designated as Capillaria sp. have been reported from G. paganellus only once (Abollo et al. 1998). In the present work, we provide description of a new species of Pseudocapillaria Freitas, 1959, which was found in the stomach of $G$. paganellus from the Vigo estuary (NW Spain).

\section{MATERIALS AND METHODS}

One hundred and four rock gobies (Gobius paganellus) were collected between October 2008 and November 2009 in the rocky shores of the Monteferro Peninsula $\left(42^{\circ} 8^{\prime}-42^{\circ} 9^{\prime} \mathrm{N}\right.$; $\left.8^{\circ} 49^{\prime}-8^{\circ} 50^{\prime} \mathrm{W}\right)$, located in the southern coast of the Vigo estuary (NW Spain). Fish were captured with hand nets and transported to the laboratory, where they were maintained in aerated aquaria until euthanized by an overdose of anaesthetics. Specimens were then measured, weighed and necropsied. The gastrointestinal tract was dissected and divided in four portions (oesophagus - stomach, and anterior, middle and posterior intestine), which were examined for helminths under the stereomicroscope.

Nematodes were gently removed from the stomach wall, washed in saline, fixed and preserved in 70\% ethanol, and examined microscopically after clearing with lactophenol. Measurements were made using a calibrated eyepiece micrometre. Digital photographs were taken using an Olympus SC30 camera on an Olympus BX41 microscope. All measurements are in micrometres unless otherwise indicated. Digital drawings were made with the aid of an Olympus microscope drawing attachment and the software CorelDraw Graphics Suite 12.

To confirm the presence/absence of a dorsal cuticular membrane interconnecting the caudal lobes of male specimens, some nematodes were processed for scanning electron microscopy as described by Segade et al. (2011), with minor modifications. Briefly, nematodes were fixed in $2.5 \%(\mathrm{v} / \mathrm{v})$ glutaraldehyde in cacodylate buffer, postfixed in $1 \%$ osmium tetroxide, dehydrated in ethanol, critical-point dried, gold-coated with a sputter coater, and observed and photographed with a Philips XL30 scanning electron microscope (Philips, Eindhoven). Parasito- 
logical parameters (prevalence, mean intensity and range of intensities) were used according to Bush et al. (1997).

\section{RESULTS}

\section{Pseudocapillaria moraveci sp. $\mathrm{n}$.}

Figs. 1-26

General: Small, filiform nematodes. Cuticle with very fine transverse striations (Fig. 13). Anterior end of body narrow, rounded, with a dome-shaped oral protuberance and a distinct post-oral transverse cephalic groove (Figs. 2, 11, 12). Two inconspicuous lateral bacillary bands extending along almost whole body length. Muscular oesophagus with a distinctly thickened last third (nearly twice thicker than anterior two-thirds) (Figs. 1, 14, 15). Stichosome consisting of single row of 25-38 stichocytes with distinct transverse annulae and conspicuous nuclei (Fig. 3). Two wing-like cells present at oesophago-intestinal junction (Fig. 3).

Male (based on 26 mature specimens; range and measurements of holotype in parentheses): Length of body 2.42-4.18 (3.30) mm, maximum width 35-55 (55). Width of lateral bacillary bands at region of posterior end of oesophagus 16-20 (19). Length of entire oesophagus $0.87-1.43$ (1.18) $\mathrm{mm}$, representing 33.2-46.1\% (35.7\%) of body length. Length of muscular oesophagus and stichosome 107-252 (230) and 0.71-1.22 (0.95) mm, respectively; 25-37 (28) stichocytes. Nerve ring situated 46-99 (57) from anterior extremity. Spicule smooth and lightly sclerotized, 180-292 (244) in length (representing $4.9-7.9 \%$ of body length), curved, with proximal end expanded and oblique in lateral view, middle part narrowed, distal end gradually narrowing to almost pointed tip (Figs. 7, 10, 17, 18). Spicule sheath not spiny, but with fine transverse striations (Figs. 7, 16, 22). Posterior end of body rounded, with two small, round ventrolateral lobes, each bearing a basal internal papilla that gives lobes a bilobulated appearance in lateral view (Figs. 8, 9, 19-22). Dorsal cuticular membrane between ventrolateral lobes absent (Figs. 21, 22). Tail short, 4-8 (8) in length.

Female (based on 26 gravid specimens; range and measurements of allotype in parentheses): Length of body 4.31-7.65 (5.57) mm, maximum width 55-80 (75). Width of lateral bacillary bands at region of posterior end of oesophagus 24-42 (44). Length of entire oesophagus $1.51-2.18$ (1.67) $\mathrm{mm}$, representing 24.8-38.3\% (30.0\%) of body length. Length of muscular oesophagus and stichosome 150-290 (210) and 1.27-1.94 (1.46) mm, respectively; 26-38 (34) stichocytes. Nerve ring situated 33-97 (59) from anterior extremity. Vulva without appendage or elevated lips, located 1.6-2.2 (1.7) $\mathrm{mm}$ from anterior end of body, at $25.0-33.9 \%$ (30.1\%) of body length, 7-22 (7) posterior to oesophagus-intestinal junction (Figs. 3, 23). Vagina short, muscular (Figs. 3, 23). Eggs 55-67 × 21-27, ellipsoid slightly equatorially narrowed, with two-layered wall (inner layer hyaline, outer layer with fine superficial net-like sculpture), slightly protruding polar plugs and uncleaved content (Figs. 5, 6, 25, 26); eggs arranged in single file in uterus. Caudal end blunt, with anus terminal or almost terminal (Figs. 4, 24).

Type host: Rock goby, Gobius paganellus Linnaeus (Perciformes, Gobiidae).

Site of infection: Stomach.

Type locality: rocky shores of Monteferro Peninsula $\left(42^{\circ} 8^{\prime}-42^{\circ} 9^{\prime} \mathrm{N} ; 8^{\circ} 49^{\prime}-8^{\circ} 50^{\prime} \mathrm{W}\right)$ in the southern coast of the Vigo estuary (NW Spanish Atlantic coast); collected between October 2008-November 2009.

Prevalence and intensity: $75 \%$ (78 infected/104 examined); 1-26 (mean 7.4) specimens per infected fish.

Deposition of type specimens: Holotype (MNCN 11.01/73), allotype (MNCN 11.01/74) and two paratypes (male and female; MNCN 11.01/75-76) deposited in the Invertebrate Collection of Museo Nacional de Ciencias Naturales (MNCN, Madrid, Spain). Two paratypes (male and female; IPCAS N-1006) deposited in the helminthological collection of the Institute of Parasitology, Biology Centre of the Academy of Science of the Czech Republic, České Budějovice.

Etymology: The species is named in honour of Dr. František Moravec (Institute of Parasitology, Biology Centre of the Academy of Sciences of the Czech Republic), in recognition of his exceptional contribution to the knowledge of capilariid nematodes.

Remarks. Eighteen species belonging to the genus Pseudocapillaria have been reported in fishes (Luo 2001, Moravec 2001, Hobbs and Hassan 2010, Moravec and Justine 2010). One of them, P. decapteri (Luo, 2001), originally described as Capillaria decapteri in Decapterus maruadsi (Temminck and Schlegel) (Carangidae, Perciformes) from Taiwan Strait (Luo 2001), has been recently transferred to the genus Pseudocapillaria by Moravec and Justine (2010). Excluding $P$. decapteri, all of the remaining species have been assigned to subgenera Indocapillaria De et Maity, 1995, Discocapillaria De et Maity, 1996, Ichthyocapillaria Moravec, 1982, and Pseudocapillaria Freitas, 1959 based on the presence/absence of a vulvar appendage in gravid females, and ventral precloacal lobe-like elevation and dorsal cuticular membrane interconnecting both ventrolateral caudal lobes in males (Moravec 2001, Hobbs and Hassan 2010, Moravec and Justine 2010).

The absence of a vulvar appendage, precloacal lobelike elevation and dorsal cuticular membrane in the specimens described in the present work confirms that P. moraveci sp. n. belongs to the subgenus Pseudocapillaria. The absence of the latter structure was confirmed by using SEM. Since this membrane may be difficult to demonstrate with light microscopy, SEM is an excellent alternative for accurately discriminating between species of the subgenera Ichthyocapillaria (dorsal cuticular membrane present) and Pseudocapillaria (membrane absent).

Considering the difficulty of detecting this taxonomic character with light microscopy, we have included, for comparative purposes, all species of both subgenera that 

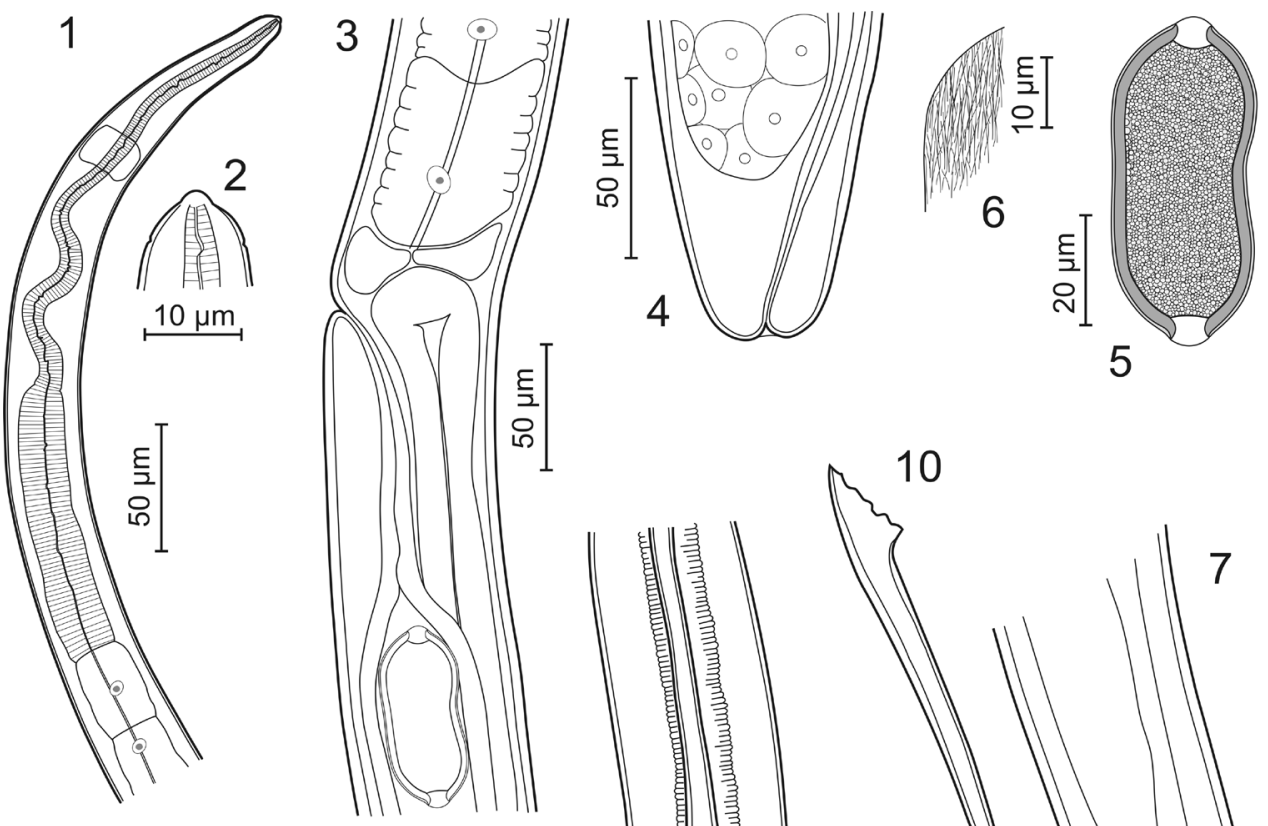

5
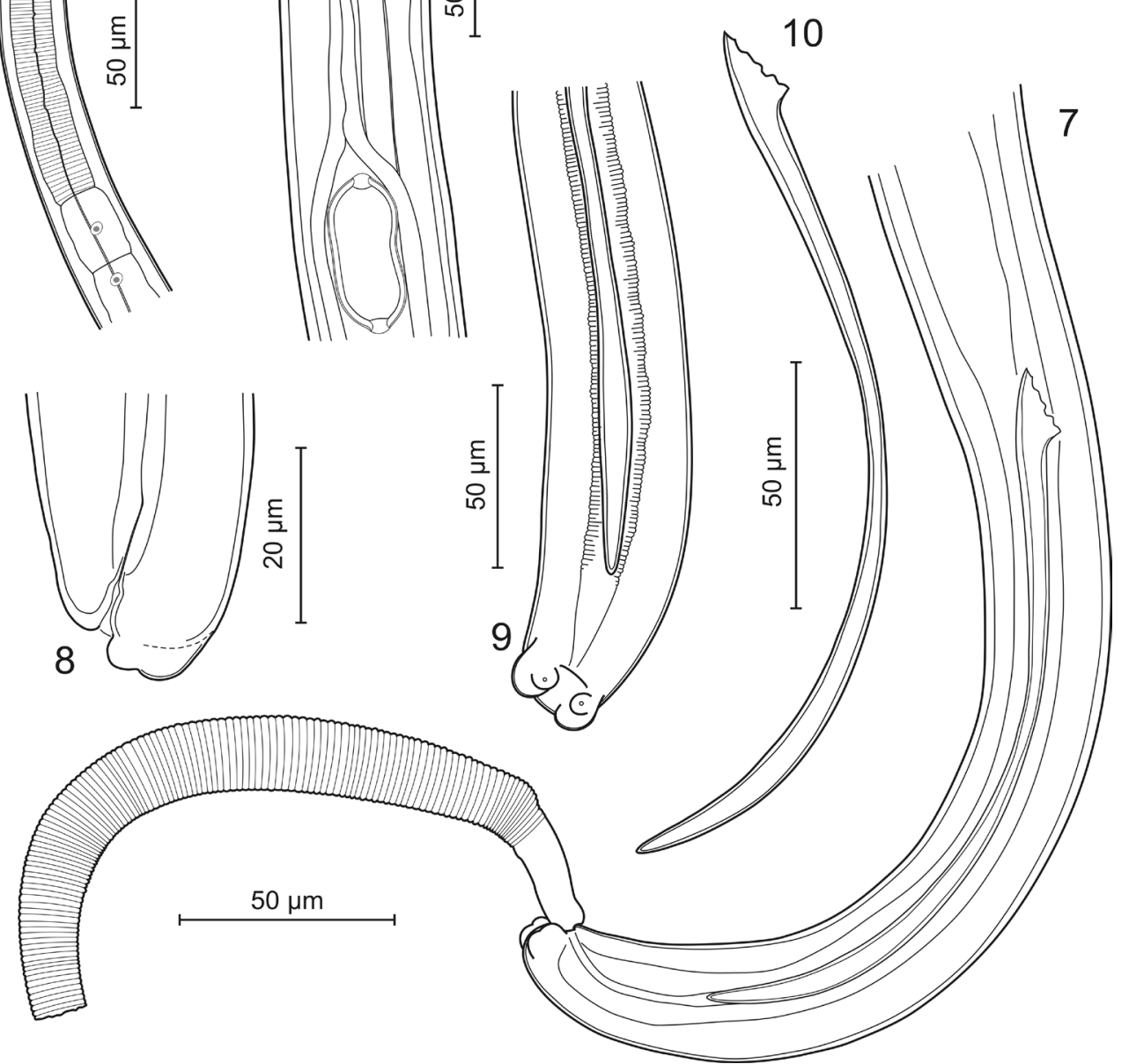

Figs. 1-10. Pseudocapillaria moraveci sp. n. 1 - anterior end of female; 2 - detail of the dome-shaped oral protuberance and the postoral transverse cephalic groove; $\mathbf{3}$ - region of oesophago-intestinal junction of female, lateral view; $\mathbf{4}$ - posterior end of female, lateral view; $\mathbf{5}$ - fully developed egg; $\mathbf{6}$ - detail of the superficial net-like sculpture of egg; $\mathbf{7}$ - posterior end of male with the spicular sheath extruded, lateral view; 8 - detail of the caudal end of male, lateral view; 9 - caudal end of male, ventral view; 10 - spicule, lateral view.

have been described in marine teleosts. Thus, although 15 species have been described in both subgenera, only eight of them have been found in marine environments (main characteristics are summarized in Table 1; see also Moravec 2001, Hobbs and Hassan 2010, Moravec and Justine 2010).

Pseudocapillaria moraveci can be easily differentiated from all these species by its unique muscular oesophagus exhibiting a distinctly thickened last third and the terminal or almost terminal anus in female specimens. In addition, males of $P$. adriatica (Nikolaeva et Naidenova, 1964)
Moravec, 1982, P. echenei (Parukhin, 1967) Moravec, 1982 and $P$. novaecaledoniensis Moravec et Justine, 2010 have dorsal cuticular membrane interconnecting the caudal lobes, being therefore included in the subgenus Ichthyocapillaria (Moravec 2001, Moravec and Justine 2010).

Besides these differences, the male of $P$. adriatica (no females have been described to date) is smaller, its entire oesophagus occupies more than half of the body length, its spicule is shorter $(0.167 \mathrm{~mm})$ and lacks a narrowed middle region (Moravec 2001). Pseudocapillaria echeneis, which has an Indo-Pacific distribution, meas- 


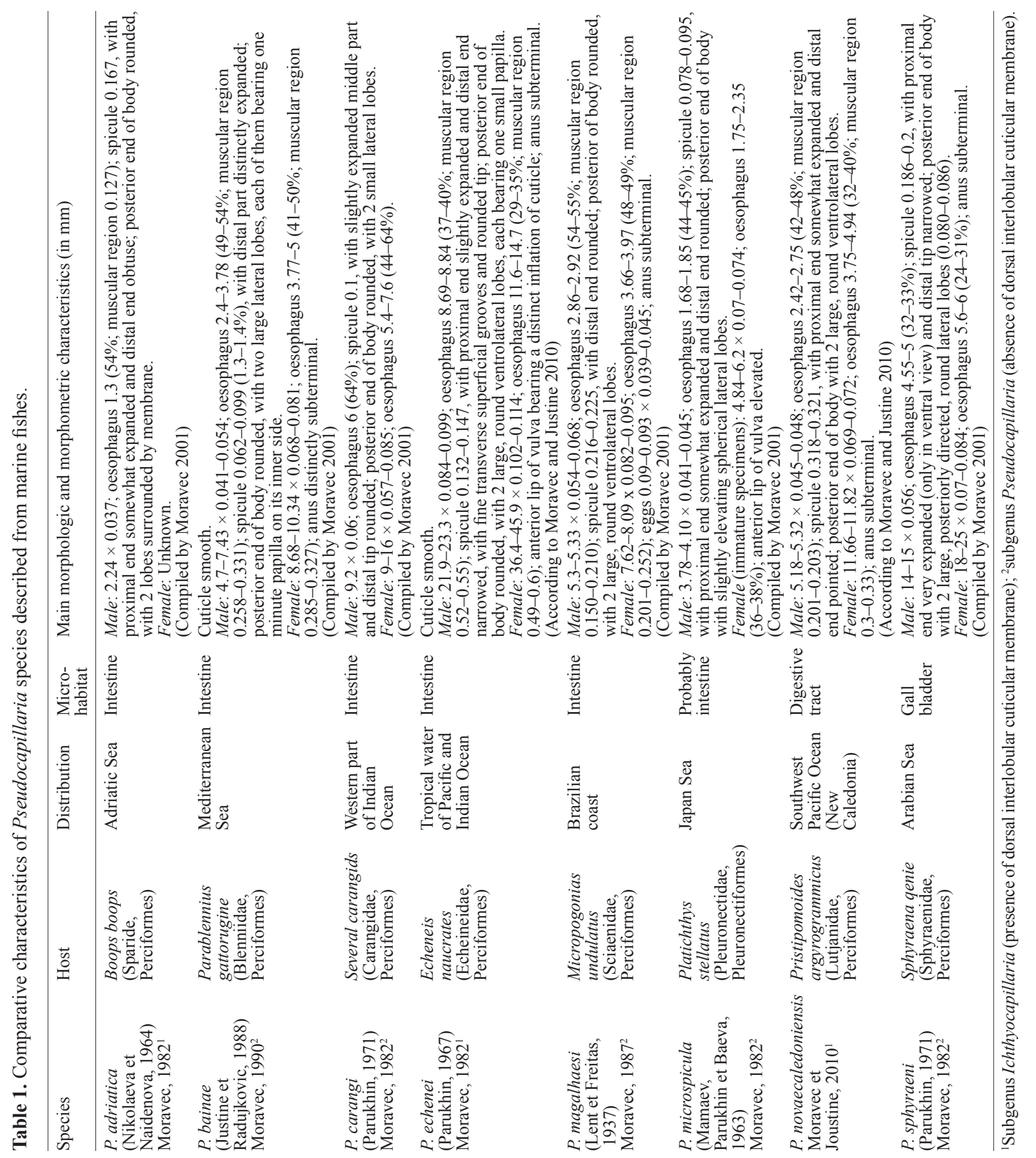

ures more than $20 \mathrm{~mm}$ in length, its spicule is shorter $(<0.15 \mathrm{~mm})$ and of a different shape, the caudal lobes in male lacks basal papillae, and the anterior lip of vulva in female specimens has a distinct cuticular inflation (Moravec and Justine 2010). Pseudocapillaria novaecaledoniensis is twice as long as $P$. moraveci, its spicule is slightly longer and lacks the middle narrowed region, and the caudal lobes also lack basal papillae (Moravec and Justine 2010).

Regarding the five marine species included in the subgenus Pseudocapillaria, P. bainae (Justine et Radu-

jkovic, 1988) Moravec, 1990, which has been described from the bleniid Parablennius gattorugine (Linnaeus) in the Mediterranean Sea, can also be differentiated from P. moraveci by its longer body and the very short spicule (<0.1 mm in length) (Moravec 2001). Pseudocapillaria carangi (Parukhin, 1971) Moravec, 1982 and P. sphyraeni (Parukhin, 1971) Moravec, 1982, both reported from fishes in the Western Indian Ocean, are more than twice longer than $P$. moraveci and their males possess caudal lobes different in appearance from those of $P$. moraveci (in $P$. sphyraeni, these structures are elongated and pos- 

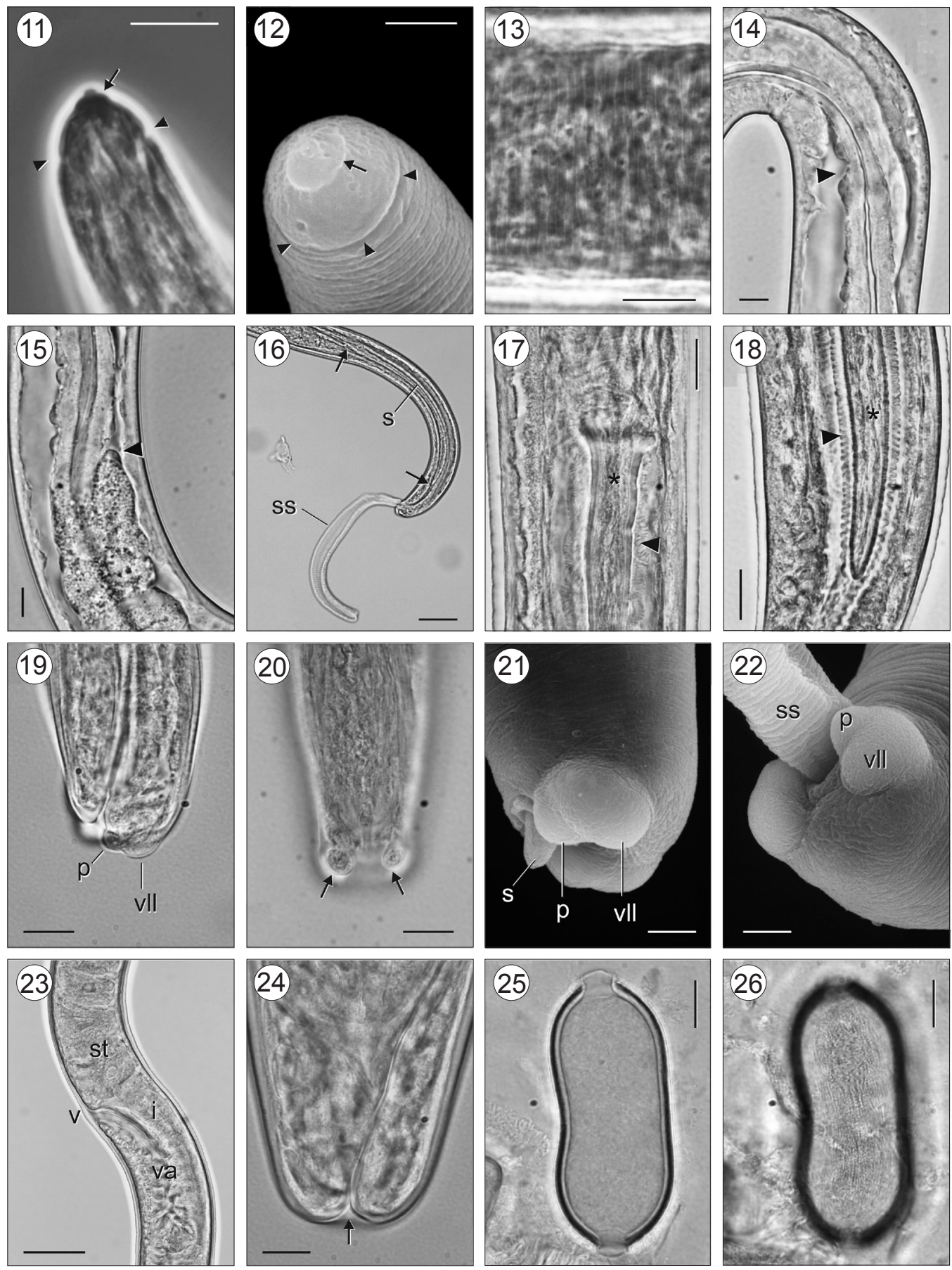

Figs. 11-26. Pseudocapillaria moraveci sp. n. 11, 12 - anterior end of female showing the dome-shaped oral protuberance (arrow) and the post-oral transverse cephalic groove (arrowheads) with phase contrast microscopy (11) and scanning electron microscopy (SEM) (12); 13 - detail of cuticular transverse striations (phase contrast microscopy); 14 - unfixed specimen showing the transition zone (arrowhead) between the anterior two-thirds and the thickened last third of muscular oesophagus; $\mathbf{1 5}$ - transition zone (arrowhead) between the muscular oesophagus and the stichosome (unfixed specimen); $\mathbf{1 6}$ - posterior end of male, in lateral view, with the spicule (s; proximal and distal ends indicated with arrows) and the spicule sheath (ss) extruded; 17, 18 - proximal (17, ventral view) and distal (18, lateral view) ends of spicule (asterisks), spicule sheath is indicated with arrowheads in both figures; 19, 20 - caudal end of male, in lateral (19) and ventral (20) view, note bilobulated appearance of the ventrolateral lobe (vll) in lateral view, as a result of the presence of the basal internal papilla (p); only basal internal papillae (arrows) are focused in 20; 21, 22 - SEM micrographs of the caudal end of male; note the absence of a dorsal cuticular membrane interconnecting both caudal lobes; $\mathbf{2 3}$ - region of vulva, lateral view ( $\mathrm{i}$ - intestine; st - stichosome; v - vulva; va - vagina); $\mathbf{2 4}$ - caudal end of female, lateral view, note the terminal position of anus (arrow); 25, 26 - egg with slightly protruding polar plugs (25) and net-like superficial appearance of the outer layer (26). Scale bars in Figs. 11, 13-15, 17-20 and 24-26 = $10 \mu \mathrm{m}$; in Figs. 12, 21 and $22=5 \mu \mathrm{m}$; in Figs. 14 and $23=50 \mu \mathrm{m}$. 
teriorly directed) and lacking basal papillae (Moravec 2001). The spicule of $P$. carangi is also shorter $(0.1 \mathrm{~mm})$, as in P. microspicula (Mamaev, Parukhin et Baeva, 1963) Moravec, 1982, a species that also lacks the basal papillae and has the anterior lip of the vulva elevated (Moravec 2001).

Pseudocapillaria magalhaesi (Lent et Freitas, 1937) Moravec, 1987 can also be differentiated from $P$. morave$c i$ by its long oesophagus occupying more than half of the body length, and the absence of basal papillae and the body length, the absence of basal papillae, and the spicule lacking a middle narrowed region. In addition, the eggs of this species are clearly different in shape and size ( $>0.09 \mathrm{~mm}$ in length; Moravec 2001).

Besides the eight species compared above, $P$. decapter $i$ and $P$. tomentosa (Dujardin, 1843) Moravec, 1987 (not included in Table 1), a typical freshwater parasite that may be found in certain estuarine environments, should also be compared with $P$. moraveci. Pseudocapillaria decapteri specimens, however, are in both sexes longer than $9 \mathrm{~mm}$ and the spicule is very short $(0.105 \mathrm{~mm}$ - Luo 2001), whereas those of $P$. tomentosa are also longer in most cases, the spicule is slightly longer $(0.24-0.33 \mathrm{~mm})$ and lacks a narrowed middle region, the caudal lobes of male lack basal papillae, the anterior lip of the vulva is elevated, and the female anus is clearly subterminal (Moravec 2001). In spite of these differences, P. tomentosa is, apart from the new species described herein, the only member of the genus Pseudocapillaria that has been reported from gobiids (i.e. Neogobius pallasi [Berg] and Ponticola gorlap [Iljin] - Moravec 2001).

Apart from the morphological differences discussed above, the microhabitat of $P$. moraveci in the alimentary canal of $G$. paganellus was clearly restricted to the stomach (this finding was also confirmed by histological studies; data not shown), contrasting with the intestinal or gall bladder microhabitats reported for most of the other species compared in this study (see Table 1). In P. novaecaledoniensis and P. microspicula, the precise microhabitat remains unknown, probably because of the technique used for collecting this species (i.e. gut wash method; Moravec and Justine 2010).

The results presented herein strongly suggest that nematodes previously reported from the stomach of $G$. paganellus from the Vigo estuary by Abollo et al. (1998) and designated as Capillaria sp. were most probably misidentified and may be conspecific with $P$. moraveci.

Acknowledgments. This work was partially supported by grants INCITE09ENA310047ES and IN8458-2010/166 (Xunta de Galicia). The authors wish to thank Dr. František Moravec (Institute of Parasitology, Biology Centre of the Academy of Sciences of the Czech Republic, České Budějovice) for his useful comments and for providing his excellent book 'Trichinelloid Nematodes Parasitic in Cold-Blooded Vertebrates'. We also wish to express our gratitude to J. Méndez and I. Pazos from C.A.C.T.I. (Centro de Apoio Científico e Tecnolóxico á Investigación; Universidade de Vigo) for technical assistance in SEM studies. Research stay of Luisa Centeno was funded by Instituto Nacional de Investigaciones Agrícolas (Venezuela).

\section{REFERENCES}

Abollo E., Gestal C., Pascual S. 1998: Parasites in the rock goby Gobius paganellus L. (Pisces: Gobiidae) and the shanny Lipophrys pholis (L.) (Pisces: Blenniidae) in NW Spain. Bull. Eur. Assoc. Fish Pathol. 18: 162-164.

Bush A.O., Lafferty K.D., Lotz J.M., Shostak A.W. 1997: Parasitology meets ecology on its ows terms: Margolis et al. revisited. J. Parasitol. 83: 575-583.

Engin S., Seyhan K. 2009: Biological characteristics of rock goby, Gobius paganellus (Actinopterygii: Perciformes: Gobiidae), in the south-eastern Black Sea. Acta Ichthyol. Piscat. 39: $111-118$

Faria C., Almada V. C. 1999: Variation and resilience of rocky intertidal fish in Western Portugal. Mar. Ecol. Prog. Ser. 184: 197-203.

Fricke R., Bilecenoglu M., Sari H.M. 2007: Annotated checklist of fish and lamprey species of Turkey, including a Red List of threatened and declining species. Stuttgarter Beitr. Naturkd. Ser. A. 706: 1-169.

Hobbs R.P., Hassan M. 2010: Pseudocapillaria (Ichthyocapillaria) nannupensis sp. $\mathrm{n}$. (Nematoda: Capillariidae) from the intestine of the freshwater cobbler Tandanus bostocki (Plotosidae) from Southwestern Australia. Comp. Parasitol. 77: 20-24.

IbáÑez M., Miguel I., SAn Millán M.D., Ripa M.I. 1989: Intertidal ichthyofauna of the Spanish Atlantic coast. Sci. Mar. 53: 451-455.
Luo D.M. 2001: Notes on nematodes of fishes from Taiwan Strait I (Nematoda: Trichocephalida: Capillariidae; Spirurida: Dracunculidae). Act. Zootax. Sin. 26: 154-161. (In Chinese, with abstract in English.)

Mazé R.A., Fuertes B., Pena J.C. 2006: Patrones de distribución de los peces intermareales de algunas pozas rocosas de la costa cantábrica (Norte de España). Bol. R. Soc. Esp. Hist. Nat. (Sec. Biol.) 101: 37-43.

Miller P.J. 1986: Gobiidae. In: P.J.P. Whitehead, M.L. Bauchot, J.C. Hureau, J. Nielsen and E. Tortonese (Eds.), Fishes of the North-eastern Atlantic and the Mediterranean. Vol. III. Unesco, Paris, pp. 1019-1085.

Moravec F. 2001: Trichinelloid nematodes parasitic in ColdBlooded Vertebrates. Academia, Prague, 429 pp.

Moravec F., Justine J.-L. 2010: Some trichinelloid nematodes from marine fishes off New Caledonia, including description of Pseudocapillaria novaecaledoniensis sp. nov. (Capillariidae). Act. Parasitol. 55: 71-80.

Segade P., Crespo C., García N., García-Estévez J.M., Arias C., Iglesias R. 2011: Brachylaima aspersae sp. n. (Digenea: Brachylaimidae) infecting farmed snails in NW Spain: morphology, life cycle, pathology, and implications for heliciculture. Vet. Parasitol. 175: 273-286. 